Brit. J. vener. Dis. (1961), 37, 284.

\title{
AN UNUSUAL CASE OF VAGINAL TUMOUR*
}

\section{BY}

\author{
R. R. WILLCOX
}

St. Mary's Hospital, London

\section{Case Report}

A young unmarried woman aged 24 years, suffering from cancerophobia, came to the clinic in an acute anxiety state, convinced that she had a malignant growth, having, she stated, only that morning felt a hard lump in the vagina.

She was a well-nourished person and there was no history of loss of weight, menstrual irregularity, or vaginal discharge; nor was there any previous history of gynaecological or other relevant disorder. She did, however, exhibit signs of emotional distress with sweaty palms and tachycardia.

Examination.-A large, hard, smooth lump filled the vagina. On removal it was found to be a globular circumscribed object, possessing no capsule, and on section was seen to have a laminated structure (Figure). It was identified as a specimen of "liliaceaeoma"-or an Allium cepa.

The encyclopaedia defines the Allium cepa as one of the family Liliaceae. It has been cultivated from ancient times and probably originated in Asia. The edible part is the bulb containing an acrid volatile oil, giving a strong flavour. The allium is a biennial, the common species producing a bulb in the first season and seeds in the second. The example shewn is evidently of the first season.

Result.-On being informed that she had no cancer, but rather an onion, the patient shewed no signs of pleasure or of gratitude on being so quickly cured of her complaint and relieved of her anxiety. Instead she exhibited signs of anger, the reason for which was the same as had caused the presence of this unexpected vegetable in such an unusual garden. It appeared that her male consort and herself had indulged very freely in alcohol on the previous evening and that he had departed at some time during the

*Paper read at the M.S.S.V.D. meeting in Paris on May 12, 1961.

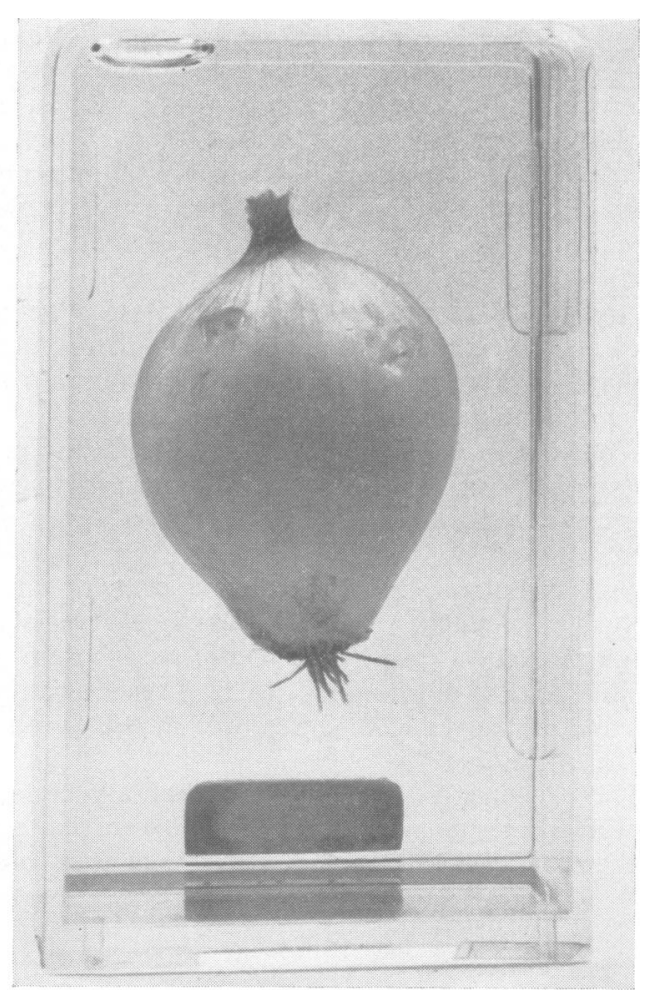

night leaving her in a deep sleep on the bed. The removal of the onion from a bunch of its fellows hanging on the back of the door, and its subsequent insertion, had been his parting gesture of affection. 